Como citar: Baldissera, D., Paim, K., Predebon, B. M., \& Feix, L. F. (2021). Contribuições da Terapia do Esquema em relacionamentos conjugais abusivos: uma revisão narrativa. PSI UNISC, 5(1), 51-67. doi:

10.17058/psiunisc.v5i1.15386

\title{
Contribuições da Terapia do Esquema em relacionamentos conjugais abusivos: uma revisão narrativa
}

\author{
Contribuciones de la Terapia de Esquemas a las relaciones conyugales abusivas: una \\ revisión narrativa
}

\section{Contributions of Scheme Therapy to abusive conjugal relationships: a narrative review}

Daniela Baldissera

Centro Universitário Metodista (IPA), Porto Alegre - RS/Brasil ORCID: 0000-0003-4323-8599

E-mail: danielabaldissera@ outlook.com

Kelly Paim

Consultório particular Valência Psicoterapia, Porto Alegre - RS/Brasil ORCID: 0000-0001-5386-8207

E-mail: kelly@valenciapsicoterapia.com.br

Betina Munero Predebon

Consultório particular Wainer Psicologia, Porto Alegre - RS/Brasil ORCID: 0000-0002-2075-1800

E-mail: betinapredebon@gmail.com

Leandro da Fonte Feix

Centro Universitário Metodista (IPA), Porto Alegre - RS/Brasil ORCID: 0000-0002-3902-358X

E-mail: leandro.feix @ipa.metodista.br

\begin{abstract}
Resumo
A violência contra a mulher é um fenômeno complexo que pode resultar em agravos à saúde. A partir de uma revisão narrativa da literatura, este estudo busca revisar as contribuições da Terapia do Esquema (TE) nos relacionamentos amorosos que apresentam violência contra a mulher perpetrada pelo parceiro íntimo. Em caso de violência conjugal, identifica-se as necessidades básicas não supridas, os Esquemas Iniciais Desadaptativos (EIDs), os estilos de enfrentamento e os modos esquemáticos do casal, como também, reconhece os aspectos culturais que permeiam a vida dos parceiros íntimos. A TE oferece sustentação teórica para analisar a influência de padrões esquemáticos nos relacionamentos abusivos. Amplia-se, portanto, o conhecimento de questões psicológicas que contribuem para que a mulher permaneça em relacionamentos com presença de violência, da mesma forma que se disponibilizam intervenções terapêuticas que auxiliam na modificação do padrão de interação destrutivo estabelecido pelo casal, sendo este principal foco e contribuição. O estudo aborda a complexidade do fenômeno da violência nos relacionamentos afetivo-conjugais e elenca fatores individuais e coletivos que interferem na problemática. A permanência em um relacionamento conjugal abusivo e mesmo a escolha do parceiro íntimo podem estar associados à manutenção de um esquema. Faz-se necessário intervenção psicológica direcionada à modificação dos EIDs em associação ao estabelecimento de medidas legais de proteção. Evidencia-se a necessidade de maior produção de pesquisas na área, principalmente para viabilizar práticas psicológicas preventivas e protocolo de tratamento específico para situações de violência afetivo-conjugal.
\end{abstract}

Palavras-chaves: Terapia do Esquema; Terapia Cognitivo-Comportamental; Violência contra a mulher; Violência por parceiro íntimo.

\section{Resumen}

La violencia contra la mujer es un fenómeno complejo que genera problemas de salud. Con base en una revisión narrativa de la literatura, este estudio busca revisar los aportes de la Terapia de Esquemas (ET) en las relaciones románticas que presentan violencia contra la mujer perpetrada por una pareja íntima. En el caso de la violencia conyugal, se identifican las necesidades básicas insatisfechas, los Esquemas Maladaptativos Tempranos (EMTs), los estilos y respuestas de afrontamiento y los 
ciclos esquemáticos de la pareja, así como el reconocimiento de los aspectos culturales que permean la vida de las parejas íntimas. TE ofrece apoyo teórico para analizar la influencia de patrones esquemáticos en las relaciones abusivas. Por tanto, se amplía el conocimiento de los aspectos psicológicos que contribuyen a que la mujer permanezca en las relaciones con la presencia de la violencia, de la misma manera que se dispone de intervenciones terapéuticas que ayudan a modificar el patrón de interacción destructiva que establece la pareja. El estudio aborda la complejidad del fenómeno de la violencia en las relaciones afectivomaritales y enumera los factores individuales y colectivos que interfieren en el problema. Permanecer en una relación matrimonial abusiva e incluso elegir una pareja íntima puede asociarse con mantener un esquema. Es necesaria una intervención psicológica dirigida a modificar los EMTs en asociación con el establecimiento de medidas legales de protección. Se evidencia la necesidad de una mayor producción de investigación en el área, principalmente para posibilitar prácticas psicológicas preventivas y un protocolo de tratamiento específico para situaciones de violencia afectivo-marital.

Palabras clave: Terapia de Esquemas; Terapia Cognitivo-Conductual; Violencia contra la mujer; Violencia de pareja.

\footnotetext{
Abstract

The violence against women is a complex phenomenon that results in health problems. From a narrative review of the literature, this study aims to review the Schema
}

Therapy (ST) contributions in romantic relationships that present violence against women perpetrated by an intimate partner. In the case of conjugal violence, the basic needs not supplied are identified, as well as the enabled early maladaptive schemas (EMSs), the coping styles and the schematic cycles of the couple, as well as recognizing the cultural aspects that permeate the lives of intimate partners. ST offers theoretical support for analyzing the influence of schematic patterns on abusive relationships. Therefore, the knowledge of psychological issues that contribute for the woman to remain in relationships with the presence of violence is broadened, in the same way that therapeutic interventions are available that help to modify the destructive interaction pattern established by the couple. and contribution. The study addresses the complexity of the phenomenon of violence in affective-marital relationships and lists individual and collective factors that interfere in the problem. Staying in an abusive marital relationship and even choosing an intimate partner can be associated with maintaining a scheme. Psychological intervention aimed at modifying EMSs in association with the establishment of legal protection measures is necessary. The need for greater production of research in the area is evidenced, mainly to enable preventive psychological practices and specific treatment protocol for situations of affectivemarital violence.

Keywords: Schema Therapy; Cognitive Behavioral Therapy; Violence against women; Intimate partner violence.

\section{Introdução}

A violência contra a mulher é reconhecida como um fenômeno mundial que atinge todas as classes sociais e diferentes contextos (Amaral, Amaral \& Amaral, 2013). Expressa pela presença frequente de mulheres em serviço de saúde que se encontram ou estiveram em situação de violência em suas relações afetivo-conjugais, de forma a ser considerado um preditor de agravos à saúde, principalmente nos problemas relacionados à saúde mental (Schraiber, Barros, \& Castilho, 2010). Conforme dados da Organização Mundial da Saúde (OMS) uma em cada três mulheres em todo o mundo sofreram violência física e/ou sexual por parte do parceiro íntimo ou de terceiros durante a vida, os quais, na maioria dos casos, são de violência infligida por parceiros (Organização Pan-Americana da Saúde, 2015). Além disso, cerca de 30\% das mulheres que estiveram em relacionamento relatam ter sofrido alguma situação de violência física e/ou sexual na vida por parte de seu companheiro (World Health Organization, 2013). Apesar desses dados não expressarem a totalidade de casos de violência sofrida pelas mulheres, visto que representarem apenas os casos notificados, a incidência desse fenômeno ainda se mostra significativamente alta.

O Senado brasileiro, em sua pesquisa bianual, em 2017, constatou aumento da prevalência de mulheres que se declararam vítimas de algum tipo de violência provocada por um homem, de $18 \%$ em 2015, para 29\%, em 2017. Observou-se também a elevação do percentual de mulheres que disseram conhecer vítimas femininas de violência doméstica ou familiar, de 56\%, em 2015, para 71\% (Pesquisa DataSenado, 2017). Ainda, o número de feminicídios notificados expressou 
crescimento no Brasil em 2017, com cerca de 13 assassinatos por dia (Cerqueira et al., 2019). A Convenção Interamericana para Prevenir, Punir e Erradicar a Violência contra a mulher define a violência contra as mulheres, conforme seu art. 1, como "qualquer ato ou conduta baseada no gênero, que cause morte, dano ou sofrimento físico, sexual ou psicológico à mulher, tanto na esfera pública como na esfera privada" (Organização dos Estados Americanos, 1995). Como forma de visibilizar e problematizar a temática, a Convenção possibilitou que se reconhecesse a violência contra a mulher como uma violação dos direitos humanos, o que fez com que os Estados assumissem responsabilidades diante deste panorama. $\mathrm{O}$ primeiro marco para $\mathrm{o}$ enfrentamento da violência contra a mulher no Brasil, no campo legislativo, é a Lei 11.340, promulgada em 7 de agosto de 2006, conhecida como a Lei Maria da Penha, que passou a considerar crime todo caso de violência doméstica e familiar contra a mulher e categorizou os tipos de violência entre física, psicológica, sexual, moral e patrimonial (Lei ${ }^{\circ}$ 11.340, 2006).

Dentre os tipos de violência contra a mulher, atualmente o que se está mais em voga consiste em o abuso emocional, expressado pelos relacionamentos abusivos, que apresentam o paradoxo entre afeto, palavras e/ou atos de agressão (Diniz, 2017). A mulher ao sofrer violência, mantém-se exposta a riscos que podem comprometer a integridade de sua vida. Entretanto, quando inseridas neste tipo de relação, experimentam dificuldades em prestar queixa contra o parceiro, bem como reconhecer a situação de violência vivida (Diniz, 2017). Situações de violência contra mulher costumam estar associados à desfechos negativos em saúde, como lesões físicas, gravidez indesejada, aborto e doenças sexualmente transmissíveis, além de impactos negativos à saúde sexual, reprodutiva e problemas de saúde mental (Organização Pan-Americana da Saúde, 2015). Os diferentes tipos de violência praticada por parceiro íntimo, em menor intensidade ou severa, associam-se aos domínios dos transtornos mentais comuns em mulheres, os quais se manifestam por meio de sintomas como depressão, ansiedade e somatizações (Dos Santos \& Monteiro, 2018).

Com base na Teoria do Esquema (TE), criada por Jeffrey Young (1990, 1999), compreende-se a dinâmica conjugal a partir da química esquemática que ocorre nos relacionamentos (Paim, 2019), em que os esquemas iniciais desadaptativos (EIDs), provenientes de experiências primárias, exercem influência na personalidade e na forma que o sujeito interage em suas relações interpessoais. Nesse ínterim, a ativação de EIDs interfere nas escolhas amorosas e na permanência em relacionamentos abusivos, uma vez que os relacionamentos amorosos podem servir tanto para a cura dos esquemas quanto para auxiliar na manutenção de EIDs (Van Vreeswijk, Broersen, \& Nadort, 2012). O presente estudo busca, a partir de estudos da Psicologia, trazer a TE como recurso para o entendimento da dinâmica interacional estabelecida em relacionamentos abusivos. Portanto, o estudo tem como objetivo, por meio de uma revisão narrativa da literatura, apurar as contribuições inovadoras da teoria focada em esquemas, em especial, na manutenção de esquemas em relacionamentos íntimos que apresentam violência cometida contra a mulher, bem como, possíveis intervenções clínicas baseadas nesta abordagem.

\section{Metodologia}

Para alcançar o objetivo proposto optou-se em realizar uma revisão narrativa da literatura. A revisão narrativa possui um caráter amplo para descrever e discutir o estado da arte de um determinado assunto, sob o ponto de vista contextual ou teórico (Rother, 2007). Embora sejam consideradas de baixo impacto em termos de evidência científica, as revisões podem contribuir na discussão da temática ao levantar questionamentos e colaborando na atualização do conhecimento específico.

O processo de coleta e escolha dos materiais foi realizado de forma não sistemática no período de julho a setembro de 2019. Foram pesquisadas bases de dados científicas, tais 
como: Scielo, BVS, Pubmed e Psycinfo. Os artigos foram selecionados de forma combinada a partir das seguintes palavraschaves: violência contra a mulher, violência contra o parceiro, terapia cognitivocomportamental e terapia do esquema. Os critérios utilizados para inclusão das publicações eram ter os descritores escolhidos nas buscas, no título ou palavras-chave, ou ter explícito no resumo o escopo do presente trabalho. Além disso, os artigos deveriam estar disponíveis na íntegra. Os materiais excluídos não apresentavam os critérios de inclusão estabelecidos e/ou apresentavam duplicidade, ou seja, publicações recuperadas em mais de uma das bases de dados.

Tendo em vista o baixo número de estudos na literatura sobre essa temática específica, não foi realizado um recorte temporal. Dessa forma, foram incluídos na pesquisa monografias, livros e capítulos de livro, publicados em língua portuguesa. Por fim, estes materiais foram lidos na íntegra e analisados criticamente.

\section{Violência Contra a Mulher}

A violência doméstica apresenta-se como todo tipo de violência praticada em ambiente familiar, a qual pode acontecer entre pessoas com laços consanguíneos e/ou afetivos (Brasil \& Comissão de Defesa dos Direitos da Mulher da Câmara dos Deputados do Brasil, 2018). A questão de gênero associa-se à violência sofrida em ambiente doméstico, visto que as normas sociais naturalizam comportamentos violentos e machistas do homem, além da submissão feminina na sociedade (Guimarães \& Pedroza, 2015). Entende-se por violência de gênero as ações violentas produzidas nas relações interpessoais e em diferentes âmbitos, amparada em cenários sociais e históricos desiguais (Bandeira, 2014). O conceito "gênero" surge a partir do movimento feminista como maneira de analisar e contestar a organização social estabelecida a partir do determinismo biológico estabelecido entre o sexo feminino e o masculino (Scott, 1995).
Para além das diferenças biológicas entre homem e mulher, as construções subjetivas determinam papéis e relações sociais, ainda fundamentados em valores patriarcais. A desigualdade de gênero coloca a mulher em uma posição de subordinação perante ao homem, na qual, a violência se designa uma forma severa de manifestar a relação social desigual entre homens e mulheres (Guedes et al., 2009). Desse modo, a violência de gênero, que acomete principalmente as mulheres, faz parte de uma construção histórica de poder do homem sobre a mulher.

A cultura, com suas crenças religiosas e sociais contribuem para a naturalização de relações conjugais abusivas. O casamento pode ser um contexto oportuno para isso, devido ao fato de ser comumente reconhecido como sagrado e um importante objetivo a ser alcançado especialmente na vida das mulheres; à vista disso, o matrimônio pode legitimar comportamentos violentos ao consumar no imaginário social que "quem ama sofre" ou "o amor supera tudo" (Cardoso, Bertho, \& Paim, 2019), crenças contribuem para que relações afetivas sejam pautadas pelo sofrimento, medo e submissão. A mulher, ao estar em um relacionamento abusivo, pode permanecer na relação por diferentes fatores, dentre eles o religioso, financeiro, moral e emocional (Silva \& Sanches, 2014).

A construção do vínculo amoroso e a permanência nele possui influência dos esquemas de cada parceiro (a) na relação (Beck, Rush, Shaw, \& Emery, 2012). Esquemas são padrões cognitivos que interferem no modo que a pessoa interpreta e responde a cada experiência. Esquemas sofrem influência da cultura e se tornam cada vez mais importantes à medida que o indivíduo cresce e desenvolve o esquema (Young, Klosko, \& Weishaar, 2008). Dessa forma, as relações afetivo-sexuais constituem-se na presença de normas e aprendizados sociais, que influenciam no comportamento e na forma de enfrentar as situações conflitivas dentro dos relacionamentos. 


\section{Violência contra a mulher perpetrada por parceiro íntimo}

A violência em algumas relações afetivo-conjugais faz parte da própria comunicação entre o casal, dado que a dependência financeira e emocional, a presença de filhos e a falta de apoio encontrada pela mulher contribuem para a permanência e silenciamento da relação abusiva (Souza \& Rosa, 2006). Relações interpessoais satisfatórias são fundamentais para a qualidade de vida, no entanto, a mulher, ao se manter em um relacionamento abusivo, pode carregar crenças (esquemas) que justifiquem comportamentos e situações vividas, como pensamentos que sustentam a ideia de que a situação abusiva pode ser momentânea, ou de que o cônjuge pode mudar e muitas vezes, de que a própria vítima fez algo para merecer a violência acometida. Dentro de um relacionamento abusivo, o sujeito que sofre a violência, muitas vezes, sente dificuldade em se desvencilhar da relação. A presença de esquemas desadaptativos corresponde a um fator relevante na situação, pois são potencialmente precedentes de opressão, de violência e da permanência de padrões de relacionamento disfuncionais (De Oliveira \& Bergamini, 2018).

Experiências destrutivas na família nuclear impactam nas relações afetivas na vida adulta, de modo a validar a violência como estratégia de resolução de conflito na relação amorosa (Colossi, Marasca, \& Falcke, 2015). A prática de violência no âmbito do namoro pode estar ligada à vivência de experiência semelhante no contexto familiar, compreendida pela ótica transgeracional, que reconhece a reprodução de comportamentos aprendidos (Oliveira, Sani, \& Magalhães, 2012). A necessidade não correspondida de segurança e apego não interfere no funcionamento das relações conjugais (Mendes \& Maia, 2019), já que a dinâmica de uma relação amorosa permeia-se às necessidades individuais de cada parceiro, com as questões de privação, rejeição, subestimação ou superestimação do sistema de apego.
Desse modo, relacionamentos amorosos podem tanto oportunizar a satisfação de demandas primárias, como repetir padrões de comportamentos originários da ativação de esquemas (Scribel, Sana, \& Benedetto, 2007). Nos relacionamentos íntimos, reconhece-se que a forma mais comum de violência contra as mulheres se constitui aquela cometida por parceiros ou ex-parceiros do sexo masculino, embora possa haver relações em que a mulher pratica a violência contra o parceiro, ou nas relações amorosas com a existência de violência entre parceiros do mesmo sexo (World Health Organization, 2013).

\section{Teoria do esquema e violência conjugal}

Os Esquemas Iniciais Desadaptativos (EIDs) são "padrões emocionais e cognitivos autoderrotistas iniciados nas etapas iniciais do desenvolvimento" (Young et al., 2008). Consistem em modelos de funcionamento que repercutem na maneira pela qual o sujeito percebe e interage consigo e com o mundo externo. O desenvolvimento dos EIDs relaciona-se com a base genética do temperamento, com as necessidades básicas a serem supridas pelos cuidadores durante a infância e com experiências nocivas vivenciadas (Wainer, 2016) Os EIDs encontram-se agrupados em cinco grandes domínios, que representam as necessidades emocionais básicas de uma criança não supridas pelos cuidadores.

$\mathrm{Na}$ etapa evolutiva, os EIDs ligados ao domínio de desconexão e rejeição consistem na frustração da necessidade de carinho, segurança, empatia e amor. Já o domínio de autonomia e desempenho prejudicados expressa o não alcance de autonomia para sobreviver de forma independente. O estágio responsável por limites prejudicados aponta o descumprimento de regras, ausência de limites e responsabilidade com os demais. $\mathrm{Na}$ etapa posterior, denominada orientação para o outro, há atendimento das necessidades e dos desejos dos outros em detrimento dos seus próprios, na busca por aprovação. Por fim, o último domínio, supervigilância e inibição, apresenta bloqueio de autoexpressão e relaxamento, 
qual demonstra padrões inflexíveis e inibição emocional (Cazassa \& Oliveira, 2008).

Os EIDs se ativam na vida adulta por acontecimentos que remetem a experiências vividas na infância. Mesmo sendo causa de sofrimento, o esquema mantém padrões emocionais e de comportamentos já conhecidos e confortáveis ao sujeito (Boscardin \& Kristensen, 2011). Para Wainer e Rijo (2016), os processos esquemáticos (PE) correspondem a ações internas e externas influenciadas pelos EIDs, que integram os estilos de enfrentamento (Wainer \& Rijo, 2016). Os PE contribuem com a adaptação do indivíduo ao ambiente que é exposto, manifestando-se de três formas: manutenção do esquema (resignação), em que há reforço do esquema, com distorções cognitivas e padrões de comportamento autoderrotistas; evitação do esquema, em que a pessoa evita sentir emoções para bloquear pensamentos e imagens que se ativam com o esquema; e compensação do esquema, em que há comportamentos exagerados para agir de forma oposta às suas necessidades a negar a existência do esquema (Wainer \& Rijo, 2016).

Na prática, ao exemplificar os estilos de enfrentamento desadaptativos de um esquema, a resposta de resignação do EID desconfiança/abuso pode ser ilustrada como forma de $\mathrm{o}$ indivíduo escolher parceiros abusivos e permanecer no abuso. Em contrapartida, no estilo de resposta de evitação do esquema, agir de modo correspondente a isso consiste em evitar tornar-se vulnerável e acreditar em qualquer pessoa. Comportamentos hipercompensatórios podem ser expressos em relações em que um parceiro abusa do outro. Um indivíduo com o EID dependência/incompetência, ao responder a uma situação com um PE de resignação, poderá pedir para pessoas próximas que tomem as suas decisões financeiras. Já se o PE for de evitação, pode evitar assumir novos desafios. Logo, na hipercompensação, o indivíduo pode se tornar tão autossuficiente que não pede nada a ninguém (Young et al., 2008).

Os esquemas desconfiança/abuso, emaranhamento e grandiosidade/arrogo são os mais propensos a estarem relacionados à violência conjugal acometida (Paim, Madalena, \& Falcke, 2012); os EIDs emaranhamento, autossacrifício, grandiosidade/arrogo e postura punitiva demonstraram correlação significativa perante a violência sofrida. Pode-se perceber que alguns EIDs, como o esquema grandiosidade/arrogo, são associados tanto à vitimização quanto à perpetração da violência contra o (a) parceiro (a).

Em estudo realizado por Paim e Falcke (2016), as autoras apresentam os esquemas de desconfiança/abuso, defectividade/vergonha, dependência/incompetência, subjugação e isolamento social como possíveis mantenedores da violência contra o(a) companheiro(a). Este achado corrobora com a ideia de que a perpetuação de um padrão de relacionamento abusivo é sustentada pela dificuldade em lidar com as emoções ativadas na presença dos EIDs, visto que a não satisfação de necessidades iniciais são indicadores de estilos de vida pouco saudáveis (Paim \& Falcke, 2016).

Conforme Algarves, 2018 os EIDs apresentados por mulheres em situação de violência cometida por parceiro íntimo possuem correlação alta com os esquemas abandono/instabilidade e desconfiança/abuso, os quais fazem parte do domínio desconexão e rejeição, que corresponde à dificuldade de estabelecer relações estáveis e de confiança (Algarves, 2018). No domínio da autonomia e desempenho prejudicados, o esquema vulnerabilidade ao dano/doença possui forte correlação à vivência de violência conjugal, expressado pelo medo constante em relação à saúde física e mental (Algarves, 2018). Referente ao domínio orientação para o outro, o esquema autossacrifício foi o que demonstrou maior ligação, o que indica a tendência de suprir a vontade dos outros em detrimento da sua própria necessidade em uma relação (Algarves, 2018). Os esquemas negatividade/pessimismo e inibição social, no domínio supervigilância e inibição, associaram-se também à presença de relacionamentos abusivos, o que sugere atenção exagerada a aspectos negativos das 
situações, assim como inibição de sentimentos e comportamentos para evitar desaprovação (Algarves, 2018).

Crawford e Wright (2007), em estudo realizado com 301 universitários, constataram relação entre as histórias de abuso na infância, EIDs e violência conjugal. Os esquemas de desconfiança/abuso, autossacrifício e inibição emocional associaram-se à vitimização nas relações amorosas (Crawford \& Wright, 2007). Os autores também identificaram que somente os esquemas de arrogo/grandiosidade e autocontrole/autodisciplina insuficientes, (ambos do domínio limites prejudicados), correlacionam-se exclusivamente à perpetração da violência. De acordo com Paim e Falcke (2018), testemunhar comportamentos agressivos e abusivos na infância pode ser desencadeador na perpetuação da violência; todavia, não se pode estabelecer uma relação causal, pois nem todas as vítimas de abuso na infância tornam-se agressoras (Paim \& Falcke, 2018). Além disso, o estudo aponta limitação ao denominar a violência conjugal como uma questão de gênero, em que homens são agressores e mulheres vítimas, sem considerar a possível existência de uma dinâmica bidirecional violenta nos relacionamentos.

$\mathrm{Na}$ relação abusiva, especificamente, cada esquema inicial desadaptativo pode ser operado para gerar respostas de enfrentamento desadaptativas que variam conforme o estilo adotado, as quais contribuam para a ocorrência da perpetração e/ou vitimização da violência. Um sujeito em resposta de resignação ao EID abandono/instabilidade pode escolher um (a) parceiro (a) que não tem compromisso no relacionamento e, mesmo assim, manter-se muito dependente emocionalmente a ele(a), ou, na evitação, passar a evitar relacionamentos íntimos. Contudo, na resposta de enfrentamento hipercompensatório, o sujeito pode atacar o (a) parceiro (a) e manter atitudes possessivas, a perpetuar, assim, a violência (Young et al., 2008). Os modos de esquema também podem auxiliar na compreensão dos mecanismos de enfrentamento desadaptativos que inserem a violência na dinâmica conflitiva estabelecida pelos pares. A contextualização de um ciclo esquemático se dá entre parceiros que sentem necessidade intensa de estarem juntos, mas que possuem convívio conflituoso.

Exemplificando, um casal composto por um parceiro que busca controlar e atacar para aliviar a sensação de vulnerabilidade de seu modo criança: o cônjuge ao ser criticado e sofrer ameaças de término de relacionamento sente-se rejeitado, atacado e desprotegido, e assim, em resposta, utiliza-se de agressões para se sentir mais protegido. Seu controle e as agressões deixam sua esposa com raiva e descontrolada. A parceira que já sofreu violência doméstica ativa o modo criança vulnerável diante de uma postura mais agressiva do marido, e através do modo capitulador complacente protege-se da sensação de medo e perigo. Entretanto, em alguns momentos, o modo hipercompensador pode ser utilizado, a fim de humilhar e diminuir o companheiro (Paim \& Cardoso, 2019), o que caracteriza $\quad$ o $\quad$ ciclo hipercompensador/capitulador, onde um dos membros do casal mostra-se dominador e o outro passivo, para evitar retaliação. Todavia, o casal também estabelece relação pelo ciclo hipercompensador/hipercompensador, pois ambos atacam e controlam. Identifica-se no caso vozes internalizadas de figuras parentais punitivas e exigentes, a exemplo de regras de modo pais punitivos internalizados no marido, que apresentam afirmações autodepreciativas e absolutistas. Os esquemas, ao acionarem vulnerabilidades a determinadas situações, podem ser denominados como situaçõesgatilhos (gatilho-esquemática) que, ao serem identificados, servem como importante estratégia terapêutica (Paim, 2016).

\section{A terapia do esquema para problemas de relacionamentos conjugais}

Os relacionamentos afetivo-conjugais podem funcionar como mantenedores do padrão esquemático disfuncional entre os pares (Paim et al., 2012); a TE possui recursos para o entendimento da dinâmica das relações interpessoais, pois um de seus focos se baseia na mudança da cognição e comportamentos que influenciam na qualidade dos relacionamentos, 
ao passo que possibilita que o indivíduo tome consciência dos seus EIDs e dos seus processos esquemáticos (Wainer \& Rijo, 2016). A TE salienta a influência dos esquemas na escolha do parceiro e na dinâmica da relação amorosa. As necessidades emocionais não supridas do indivíduo, causadoras de sentimentos dolorosos, afetam a interação entre os parceiros, de modo que o sujeito dispõe de mecanismos para lidar com essas experiências que refletem na vida adulta (Scribel et al., 2007).

A química esquemática consiste em manter relacionamentos com parceiros que ativam padrões esquemáticos disfuncionais (Young et al., 2008). Um ciclo esquemático de ativação de respostas desadaptativas pode se estabelecer em relacionamentos afetivosexuais, os quais mantêm a perpetuação dos EIDs, sensações e crenças familiares (Paim, 2016). Alguns dos EIDs com forte química esquemática são: defectividade/vergonha e grandiosidade/arrogo, em que o indivíduo tende a buscar cônjuges com senso de superioridade em relação aos outros; nessa relação, a sensação de desvalor pode ser reforçada na arrogância do companheiro. Da mesma forma interligada, o esquema

\section{Quadro 1}

As quatro categorias de agrupamentos e os principais modos esquemáticos.

\begin{tabular}{|c|c|c|c|}
\hline Modos criança & $\begin{array}{c}\text { Modos pais } \\
\text { disfuncionais } \\
\text { internalizados }\end{array}$ & $\begin{array}{l}\text { Modos de enfrentamento } \\
\text { desadapatativos }\end{array}$ & $\begin{array}{l}\text { Modos } \\
\text { adaptativos }\end{array}$ \\
\hline $\begin{array}{l}\text { Criança vulnerável } \\
\text { Criança abandonada-abusada } \\
\text { Criança solitária-inferior } \\
\text { Criança dependente } \\
\text { Criança zangada } \\
\text { Criança enfurecida } \\
\text { Criança impulsiva/indiscipli-nada }\end{array}$ & $\begin{array}{l}\text { Pais punitivos } \\
\text { Pais exigentes }\end{array}$ & $\begin{array}{l}\text { Capitulador complacente } \\
\text { Hipercompensador } \\
\text { Autoengrandecedor } \\
\text { Provocador e ataque } \\
\text { Desconfiado/supercontrolador } \\
\text { Perfeccionista } \\
\text { Predador e manipulador } \\
\text { Modos evitativos } \\
\text { Protetor desligado } \\
\text { Protetor autoavaliador } \\
\text { Protetor zangado } \\
\text { Protetor evitativo }\end{array}$ & $\begin{array}{l}\text { Adulto Saudável } \\
\text { Criança feliz }\end{array}$ \\
\hline
\end{tabular}

Nota. Adaptado de Paim \& Cardoso, 2019 dependência/incompetência expressa a insegurança de uma pessoa na capacidade de tomar decisões ou até mesmo gerenciar a própria vida; logo, juntamente com o esquema de padrões inflexíveis, possivelmente o parceiro, ao apresentar rigidez e necessidade de controle, tome decisões pelo casal, o que pode fortalecer os EIDs de ambos. O esquema desconfiança/abuso associado ao esquema de subjugação, expressa a díade dominante/dominado, os quais equivalem a dinâmica que reproduz vivências potencialmente abusivas (Paim, 2019).

Em relacionamentos amorosos, uma espécie de ciclo esquemático de reações e respostas desadaptativas pode estabelecer interação destrutiva na relação, o que pode acarretar na invalidação e reconhecimento das necessidades emocionais do cônjuge (Paim, 2016). Isso pode ser observado através da ativação dos Modos Esquemáticos (MEs), que são caracterizados como estados emocionais momentâneos que manifestam respostas adaptativas ou desadaptativas na ativação de esquemas (Young et al., 2008). Os autores indicam dez ME, subdivididos em quatro categorias. 
Os modos esquemáticos facilitam a compreensão do funcionamento dos esquemas individuais que refletem na dinâmica conjugal. Os modos criança representam as necessidades emocionais não supridas na infância, e os modos pais disfuncionais internalizados atribuem características punitivas, o que pode gerar expectativas e padrões de exigência altos. Os modos de enfrentamento desadaptativos são reações de enfrentamento resignadoras, evitativas ou compensatórias, utilizadas para amenizar sensações de desamparo e invalidação. Os modos de enfrentamento adaptativos, todavia, criam meios e atividades saudáveis que supram suas necessidades, de maneira a expressar suas emoções de forma a não trazer prejuízos às relações sociais (Paim \& Cardoso, 2019).

Considera-se a existência de padrões básicos de ciclos de enfrentamento entre dois modos, a exemplo dos ciclos hipercompensador/hipercompensador, onde ambos os parceiros atacam-se ou controlam-se para aliviar a sensação de desamparo; o ciclo hipercompensador/capitulador complacente caracteriza-se pelo domínio da relação por um dos parceiros, enquanto o outro responde com passividade e submissão, o que pode gerar padrões abusivos; o padrão hipercompensador/protetor desligado pode ser caracterizado quando há um ataque de um dos parceiros, e o outro, em resposta, comporta-se de forma passiva, caracterizando desconexão emocional (Paim \& Cardoso, 2019).

A TE tem o objetivo de identificar os ciclos de modos mais utilizados na relação que acarretam prejuízos e insatisfações (Paim \& Cardoso, 2019). A dinâmica conjugal pode se manter pelos estilos de enfrentamento disfuncionais dos parceiros perante os ciclos de modos. A TE para casais rompe esse padrão de resposta estabelecida na interação entre os cônjuges, através do entendimento do que determinada situação desencadeada e quais gatilhos propiciam a ativação esquemática de cada companheiro, bem como o que cada um sente e como reage à situação, promovendo a reconexão afetiva do casal (Maia, 2019).

\section{Possibilidades de intervenções e técnicas}

Assim como identificar os EIDs ativados, estilos de enfrentamento utilizados, modos esquemáticos e as necessidades básicas não supridas na história de vida de cada um dos membros do casal, em situações de violência manifestada por parceiro íntimo, a intervenção deve reconhecer os aspectos culturais e o contexto em que o casal se apresenta inserido (Cardoso et al., 2019). Contudo, em casos de violência, faz-se indispensável avaliar, inicialmente, o nível de comprometimento da relação amorosa e, principalmente, realizar a intervenção com a pessoa em situação de violência de forma individual. O profissional deve mostrar-se empático, atento a possíveis riscos, e disponível para esclarecer dúvidas e notificar os casos de suspeita ou confirmação de violência, encaminhando quando necessário para os serviços especializados (Habigzang, 2018). A mulher vítima de violência deve ser orientada sobre as medidas protetivas a serem tomadas e auxiliada na organização de uma rede de apoio.

O psicólogo precisa ter uma postura ativa e resolutiva quanto à manifestação de situações de violência e os danos psicossociais sofridos. Quando há uma situação de perigo iminente, o terapeuta deve avaliar e mapear as situações de violência, bem como, orientar acerca de serviços de atendimento especializado em casos de violência. Além disso, é imprescindível a posição moral e ética sobre o caso e o manejo que favoreçam a segurança e interrompam as situações de violência (Cardoso et al., 2019).

No atendimento individual de mulheres vítimas de abuso, como forma de enfraquecer os EIDs e identificar os modos criança que estão por trás dos modos de enfrentamento, o terapeuta deve proporcionar uma relação reparadora nos atendimentos. A reparentalização limitada procura suprir as necessidades emocionais da paciente, e, assim, o terapeuta se torna um vínculo seguro, que expressa carinho, valorização, cuidado e proteção, conforme os limites terapêuticos (Wainer \& Rijo, 2016). O terapeuta auxilia a 
ativação do modo adulto saudável da paciente para que, ao longo do processo terapêutico, ela aprenda a se proteger das vivências de violência (Young et al., 2008). O terapeuta mescla estratégias cognitivas, comportamentais, vivenciais e interpessoais. Nas técnicas vivenciais, a intervenção é realizada com o esquema a nível emocional, a exemplo do uso de imagens mentais, que se mostra uma ferramenta que traz à tona o material nuclear, servindo para descobrir a origem dos esquemas, identificando-os e ressignificando as situações vividas (Young et al., 2008).

A reparentalização limitada é a principal estratégia terapêutica da TE, e mostrase fundamental no processo de intervenção, cuja função é promover experiências positivas de cuidado que não foram devidamente realizadas pelos cuidadores. Primeiramente, o terapeuta ocupa este papel, que posteriormente será substituído pelo modo adulto saudável da paciente. A reparentalização limitada pode ser aplicada por exercícios de imagem mental, em que, a partir do acesso a uma memória da infância ou adolescência, o terapeuta reescreve a cena, agindo de forma adaptativa conforme a necessidade emocional da criança (Wainer, Paim, \& Erdos, 2016).

A ativação do funcionamento de pais disfuncionais internalizados torna-se prejudicial à vida de mulheres vítimas de violência, pois, nesses casos, padrões punitivos e destrutivos são direcionados a si, com a internalização da crença que são merecedoras de raiva, ódio e abuso (Young et al., 2008). As vozes parentais internalizadas carregam crenças sociais/culturais que podem sustentar ideias abusivas de relacionamento e, dessa forma, a intervenção precisa combater as vozes punitivas internalizadas e identificar o histórico de vivências abusivas (Cardoso et al., 2019). Nesse caso, técnicas de imagens que mimetizam a proteção da criança de pais abusivos mostram-se fundamentais (Wainer \& Rijo, 2016; Young et al., 2008). A técnica de carta aos pais também é recomendada para combate ao modo pais punitivo, quando a paciente escreve uma carta à figura abusiva da sua história, ao expressar toda a mágoa e raiva pelos abusos (Young et al., 2008).

A primeira fase do atendimento conjugal visa a checagem de possíveis riscos. Sessões individuais são feitas para garantir segurança e um entendimento profundo da dinâmica violenta (Van Vreeswijk et al., 2012) e, caso necessário, realiza-se encaminhamento para outros profissionais, como forma de estabelecer uma rede de apoio segura. Ainda na fase de avaliação, deve-se também reconhecer os EIDs individuais e a operação do ciclo esquemático do casal (Paim, 2016). O processo terapêutico dependerá do setting seguro (Paim \& Torquato, 2019), assim, as sessões conjugais apenas serão realizadas quando pacientes e terapeutas se sentirem confiantes que não haverá risco. A criação e a manutenção da aliança terapêutica com o casal e o estabelecimento do contrato terapêutico apresentam-se essenciais para a efetividade da intervenção (Leitune \& Risso, 2019).

As estratégias interventivas em TE para relacionamentos abusivos visam à investigação e contato com as necessidades emocionais não atendidas, bem como, com os estilos de enfrentamento que os cônjuges usam para aliviar as sensações de tais privações, inclusive os comportamentos abusivos e submissos. Os conflitos amorosos evidenciam a mútua ativação dos modos esquemáticos desadaptativos complementares, os quais desencadeiam ciclos repetitivos de desconexão emocional. Desse modo, o casal deve se tornar consciente de seus modos esquemáticos; além disso, mostra-se importante identificar o ciclo destrutivo que se estabelece na relação, mantendo-se atento a necessidade do outro e desenvolvendo mudança nos padrões relacionais. Tão importante quanto ter conhecimento sobre os modos esquemáticos dos parceiros, é a responsabilização sobre os comportamentos desadaptativos que mantém o ciclo abusivo (Van Vreeswijk et al., 2012). O terapeuta do esquema trabalha a validação das necessidades emocionais, do mesmo modo que utiliza da confrontação empática para lidar com comportamentos destrutivos e mantenedores dos EIDs (Paim \& Torquato, 2019). 
O trabalho com ciclo de modos esquemáticos possibilita a conceitualização da problemática conjugal, em que o uso do Cartão de Embates de Ciclos pode auxiliar nessa compreensão, pois ele possibilita detectar esquemas e memórias centrais envolvidas na conflitiva e, na sequência, verifica vozes internalizadas de modos parentais e os modos de enfrentamento de cada parceiro. Demonstrase, inclusive, importante acessar a emoção que acompanha a ativação do modo criança, com intenção de conectar com as necessidades emocionais não atendidas. Como desfecho, busca-se estratégias de resolução de conflito a serem desenvolvidas a partir do modo adulto saudável dos cônjuges, com a finalidade de diminuir a utilização de modos de enfrentamento disfuncionais (Maia, 2019).

Outro enfoque necessário consiste no combate ao modo pais internalizados disfuncionais. Identificar os pensamentos críticos e punitivos auxilia na compreensão da dinâmica abusiva como uma perspectiva transgeracional internalizada e não saudável derivada de experiências familiares pregressas, em que os níveis de sofrimento foram significativos. Uma vez que os indivíduos se conectem com as dores advindas do passado, pode-se reforçar a necessidade de mudança dos padrões cognitivos e comportamentais abusivos (Young et al., 2008). A prática da cadeira vazia pode auxiliar no combate ao modo pais internalizados disfuncionais, pois, ao representar o cuidador abusivo, a cadeira vazia permite reviver cenas dolorosas de uma maneira protegida, com o estabelecimento de um espaço de fala seguro para a criança ou adolescente vítima de violência doméstica. Desta forma, a raiva pode ser expressa de forma adaptativa quando direcionada ao devido causador, ao invés de descarregada ao parceiro (Young et al., 2008). Nesta técnica, o terapeuta ajuda os cônjuges a falarem ao abusador (que está representado na cadeira vazia) todo o mal que foi feito e como se sentem, de forma a limitar o comportamento abusivo.

O foco nas emoções e nas necessidades emocionais se manifesta fundamental, assim, os cônjuges conseguem ter empatia e conexão um pelo outro. Além disso, o terapeuta ajuda os parceiros a expressarem suas emoções mais vulneráveis, como medo e tristeza (Paim, 2016; Paim \& Torquato, 2019). No processo terapêutico de casais em situação de violência, o cônjuge que usa modo de enfrentamento hipercompensação ataque, assume o papel de abusador, deve ser direcionado para emoções mais vulneráveis do modo criança.

A reparentalização limitada entre os cônjuges pode ser alcançada por meio de roleplay, onde o modo adulto saudável de um parceiro fala com o modo criança vulnerável do outro, visando atender suas necessidades emocionais (Paim \& Cardoso, 2019). Como forma de técnica imagística, o trabalho com cadeiras deve ser realizado na presença dos parceiros, de forma a romper padrões destrutivos (Paim, 2016; Paim \& Torquato, 2019). A técnica da cadeira transformacional, por exemplo, pode ser empregada para que se tenha diálogo entre vários modos esquemáticos, com a finalidade de validar e nutrir a criança vulnerável, combater os pais internalizados e trabalhar com os modos de enfrentamento (Kellogg \& Young, 2006).

Para além do manejo de comportamentos abusivos, evidencia-se a necessidade de re-elaboração da interação do casal, apresenta-se necessário auxiliar o casal a desenvolver recursos saudáveis, que supostamente estão em déficit. Para isso, utiliza-se treinamento de habilidades sociais, que contemplam noções de empatia, assertividade, comunicação, resolução de problemas, e outras, o que gera aumento do repertório comportamental e das estratégias de enfrentamento que antes estavam circunscritas aos padrões abusivos (Cardoso \& Costa, 2019).

Em muitos casos, a terapia corresponde à primeira vez em que os pacientes conseguem compartilhar seus sentimentos mais intensos, e reconhecem seus modos de enfrentamento para lidar com suas necessidades não supridas (Jacob \& Arntz, 2013). A relação terapêutica mostra-se fundamental como agente de mudança ao fornecer um ambiente de validação e empatia, com recursos necessários para 
reparar relações destrutivas do passado que interferem nas relações interpessoais no presente (Wainer et al., 2016). Dentro da terapia de casal, a TE possibilita trazer o que se tem de mais enraizado e emocional internalizado no sujeito e que permeia as suas relações amorosas.

\section{Resultados}

Os EIDs são formados a partir da interação entre o temperamento pessoal com um ambiente que não atende às necessidades emocionais básicas, e interferem no aparecimento e manutenção de padrões cognitivos e comportamentais complexos e duradouros. Cada esquema inicial desadaptativo representa um tema amplo sobre si mesmo e sobre a relação pessoal com terceiros, (que abrangem memórias, emoções, cognições, sensações corporais). Os EIDs manifestam-se quando os pais ou outros cuidadores primários são caracterizados como emocionalmente frios, imprevisíveis, hostis ou invasivos. Os padrões cognitivos formados são derrotistas, resistentes e com papel formador na identidade. As emoções negativas que acompanham são intensas e os métodos empregados para lidar com elas geralmente são questionáveis. Paradoxalmente, o EID se torna obstáculo para a satisfação das mesmas necessidades envolvidas em sua formação e na obtenção de uma vida mais significativa (Rafaeli et al., 2010; Young, 2003).

\section{Discussão}

A violência doméstica contra a mulher é um fenômeno múltiplo e complexo que tem gerado grande movimentação em nível social, moral e político. Visto que este fenômeno gera agravos em nível individual, social e de saúde, intervenções com vítimas e agressores, bem como, estratégias de promoção de saúde se fazem essenciais perante o panorama atual. Entretanto, a rede de saúde ainda se encontra escassa de recursos para lidar com essa problemática.

Atualmente, as abordagens cognitivocomportamentais se destacaram em relação às demais, tanto por seu caráter efetivo como também por questões econômicas (Costa, Delatorre, Wagner, \& Mosmann, 2017). Sabendo que os EIDs podem ser considerados variáveis mediadoras para a manutenção da violência entre casais, a TE mostra-se como uma abordagem promissora para essa problemática, visto que permite a intervenção diretiva nos processos esquemáticos, que visem o rompimento da perpetuação esquemática. Além disso, por ser mais rápida em relação às outras, pode ser uma alternativa economicamente viável em nível de saúde pública e privada.

Seu foco afetivo, psicoeducativo e resolutivo parece contribuir positivamente no prognóstico do tratamento. Entretanto, setorizar as intervenções em relacionamentos conjugais abusivos apenas dentro da psicologia se torna limitador, pois não são apenas questões esquemáticas e/ou de personalidade que influenciam na formação e perpetuação de agressores e vítimas; faz-se necessário o debate acerca do machismo estrutural em que a sociedade está inserida, uma vez que o ambiente pode interferir no desenvolvimento de relações não saudáveis.

\section{Considerações Finais}

A TE oferece sustentação teórica para analisar a influência de padrões esquemáticos nos relacionamentos abusivos. Amplia-se, portanto, o conhecimento de questões psicológicas que contribuem para que a mulher permaneça em relacionamentos com presença de violência, da mesma forma que se disponibilizam intervenções terapêuticas que auxiliam na modificação do padrão de interação destrutivo estabelecido pelo casal, sendo este principal foco e contribuição.

O estudo aborda a complexidade do fenômeno da violência nos relacionamentos afetivo-conjugais, elencando fatores individuais e coletivos que interferem na problemática. Compreendendo-se que a permanência em um relacionamento conjugal abusivo e mesmo a escolha do parceiro íntimo podem estar associados à manutenção de um 
esquema. Faz-se necessário intervenção psicológica direcionada à modificação dos EIDs em associação ao estabelecimento de medidas legais de proteção.

As possibilidades de atuação dos profissionais da Psicologia junto às redes de apoio - seja na assistência à saúde ou nas delegacias especializadas precisam dialogar com as evidências científicas sobre essa temática. Estudos como este evidenciam a necessidade de incentivo e investimento em intervenções sociais que visem promoção de novas concepções acerca do tema, quebrando padrões hierárquicos e estereotipados, promovedores das práticas punitivas, comportamentos possessivos, sentimentos indevidos de culpa e resignação ao abuso.

Visando um enfoque preventivo, é importante a constatação de que certos EIDs (como desconfiança/abuso ou defectividade/vergonha) podem se originar a partir de experiências traumáticas na infância, torna-se ainda mais relevante a intervenção psicossocial precoce em crianças e adolescentes vítimas de maus-tratos. Nesse sentido, pode-se falar na prevenção não apenas dos efeitos imediatos dos maus-tratos, mas também da atenção de consequências de longo prazo, como dificuldades persistentes em relações interpessoais no decorrer de todo o desenvolvimento. Ainda, tendo em vista que os EIDs derivam, em muitas situações, de necessidades emocionais básicas não satisfeitas, demostra-se possível pensarmos em prevenção primária a partir de programas de psicoeducação e sensibilização para pais e educadores, promovendo maior compreensão sobre a relevância de proporcionar à criança ambiente seguro, com limites, estímulos e afeto.

Por fim, apresenta-se fundamental ressaltar que o presente artigo se limitou a uma revisão narrativa, o que não o sustenta como uma fonte rigorosamente reprodutível. Além disso, os estudos e referenciais teóricos sobre terapia do esquema para relacionamentos abusivos ainda são poucos, o que também foi um limitador dos resultados. Sugere-se novos estudos empíricos com objetivos de confirmar a eficácia da terapia do esquema para compreensão e tratamento de relações conjugais abusivas.

\section{Referências}

Algarves, C. P. (2018). Esquemas iniciais desadaptativos de mulheres em situação de violência perpetrada por parceiro íntimo (Monografia de graduação). Universidade Federal do Maranhão, São Luis, Maranhão, Brasil. Recuperado de http://hdl.handle.net/123456789/2331

Amaral, N. de A., Amaral, C. de A., \& Amaral, T. L. M. (2013). Mortalidade feminina e anos de vida perdidos por homicídio/agressão em capital Brasileira após promulgação da Lei Maria da Penha. Texto e Contexto Enfermagem, 22(4), 980988. doi: $10.1590 / \mathrm{S} 0104-$ 07072013000400014

Bandeira, L. M. (2014). Violência de gênero: A construção de um campo teórico e de investigação. Sociedade e Estado, 29(2), 449-469. doi: 10.1590/S010269922014000200008

Beck, A., Rush, J. A., Shaw, B. F., \& Emery, G. (2012). Terapia Cognitiva da Depressão (1st ed.). Porto Alegre: Artmed.

Boscardin, M. K., \& Kristensen, C. H. (2011). Esquemas Iniciais Desadaptativos em Mulheres com Amor Patológico. Revista de Psicologia Da IMED, 3(1), 517-526. doi: 10.18256/2175-5027/PSICOIMED.V3N1P517-526

Lei $n^{\circ} 11.340$, de 7 de agosto de 2006. Cria mecanismos para coibir a violência doméstica e familiar contra a mulher, nos termos do $\S 8^{\circ}$ do art. 226 da Constituição Federal, da Convenção sobre a Eliminação 
de Todas as Formas de Discriminação contra as Mulheres e da Convenção Interamericana para Prevenir, Punir e Erradicar a Violência contra a Mulher; dispõe sobre a criação dos Juizados de Violência Doméstica e Familiar contra a Mulher; altera o Código de Processo Penal, o Código Penal e a Lei de Execução Penal; e dá outras providências. Recuperado de http://www.planalto.gov.br/ccivil_03/_ato2 004-2006/2006/lei/111340.htm

Brasil, \& Comissão de Defesa dos Direitos da Mulher da Câmara dos Deputados do Brasil. (2018). Mapa da Violência contra a Mulher. Recuperado de https://www2.camara.leg.br/atividadelegislativa/comissoes/comissoespermanentes/comissao-de-defesa-dosdireitos-da-mulher-cmulher/arquivos-deaudio-evideo/MapadaViolenciaatualizado200219.p df

Cardoso, B. L. A., Bertho, M. A. C., \& Paim, K. (2019). Até que a morte nos separe: a contribuição da cultura para a manutenção de esquemas iniciais desadaptativos em relacionamentos abusivos. In K. Paim \& B. L. A. Cardoso (Eds.), Terapia do esquema para casais: base teórica e intervenção (1st ed., pp. 143-163). Porto Alegre: Artmed.

Cardoso, B. L. A., \& Costa, N. (2019). Habilidades Sociais e Violência Contra a Mulher por Parceiro Íntimo: Um estudo teórico. Interação Em Psicologia, 23(1). doi: $10.5380 /$ psi.v23i1.53789

Cazassa, M. J., \& Oliveira, M. D. S. (2008). Terapia focada em esquemas: Conceituação e pesquisas. Revista de Psiquiatria Clinica, 35(5), 187-195. doi: 10.1590/S010160832008000500003

Cerqueira, D., Lima, R. S. de, Bueno, S., Neme, C., Ferreira, H., Alves, P. P., ... Armstrong, K. (2019). Atlas da Violência 2019. Recuperado de https://www.ipea.gov.br/portal/index.php?o ption $=$ com_content $\&$ view $=$ article $\& i d=347$ $\underline{84}$

Colossi, P. M., Marasca, A. R., \& Falcke, D. (2015). De Geração em Geração: A Violência Conjugal e as Experiências na
Família de Origem. Psico, 46(4), 493. doi: 10.15448/1980-8623.2015.4.20979

Costa, C. B. da, Delatorre, M. Z., Wagner, A., \& Mosmann, C. P. (2017). Terapia de Casal e Estratégias de Resolução de Conflito: Uma Revisão Sistemática. Psicologia: Ciência e Profissão, 37(1), 208-223. doi: 10.1590/1982-3703000622016

Crawford, E., \& Wright, M. O. (2007). The impact of childhood psychological maltreatment on interpersonal schemas and subsequent experiences of relationship aggression. Journal of Emotional Abuse, 7(2), 93-116. doi: 10.1300/J135v07n02_06

De Oliveira, A. M., \& Bergamini, G. B. (2018). Esquemas desadaptativos de mulheres em relacionamentos abusivos: uma discussão teórica. Revista Científica FAEMA, 9(2), 796-802. doi: 10.31072/rcf.v9i2.637

Diniz, G. R. S. (2017). Trajetórias conjugais e a construção das violências. Psicologia Clínica, 29(1), 31-41. Recuperado de http://pepsic.bvsalud.org/scielo.php?script= sci_arttext\&pid=S0103$\underline{56652017000100004}$

Dos Santos, A. G., \& Monteiro, C. F. de S. (2018). Domains of common mental disorders in women reporting intimate partner violence. Revista Latino-Americana de Enfermagem, 26, 3099. doi: 10.1590/1518-8345.2740.3099

Guedes, R. N., Silva, A. T. M. C. da, \& Fonseca, R. M. G. S. da. (2009). A violência de gênero e o processo saúdedoença das mulheres. Escola Anna Nery, 13(3), 625-631. doi: 10.1590/s141481452009000300024

Guimarães, M. C., \& Pedroza, R. L. S. (2015). Violence against women: Problematizing theoretical, philosophical and legal definitions. Psicologia e Sociedade, 27(2), 256-266. doi: 10.1590/1807$03102015 \mathrm{v} 27 \mathrm{n} 2 \mathrm{p} 256$

Habigzang, L. F. (2018). Manual de Capacitação Profissional para Atendimentos em Situações de Violência. Recuperado de https://www.cevs.rs.gov.br/upload/arquivos /201910/15154038-manual-de-capacitacao- 
profissional-para-atendimento-emsituacoes-de-violencia-pucrs.pdf

Jacob, G. A., \& Arntz, A. (2013). Schema therapy for personality disorders-A review. International Journal of Cognitive Therapy, 6(2), 171-185. doi:

10.1521/ijct.2013.6.2.171

Kellogg, S. H., \& Young, J. E. (2006). Schema therapy for borderline personality disorder. Journal of Clinical Psychology, 62(4), 445-458. doi: 10.1002/jclp.20240

Leitune, C., \& Risso, B.-H. (2019). A relação terapêutica. In K. Paim \& B. L. A. Cardoso (Eds.), Terapia do Esquema para Casais: Base Teórica e Intervenção (1st ed., Vol. 1, pp. 120-140). Porto Alegre: Artmed.

Maia, A. M. S. L. (2019). O trabalho com os modos esquemáticos com casais. In $\mathrm{K}$. Paim \& B. L. A. Cardoso (Eds.), Terapia do Esquema para Casais: Base Teórica e Intervenção (1st ed., Vol. 1, pp. 87-99). Porto Alegre: Artmed.

Mendes, M. A., \& Maia, A. M. S. L. (2019). Teoria do apego e esquemas conjugais. In K. Paim \& B. L. A. Cardoso (Eds.), Terapia Do Esquema Para Casais: base teórica e intervenção (1st ed., Vol. 1, pp. 15-29). Porto Alegre: Artmed.

Oliveira, M. S., Sani, A. I., \& Magalhães, T. (2012). O contágio transgeracional da agressividade: a propósito da violência no namoro. Revista Portuguesa Do Dano Corporal, 23, 175-188. doi: 10.14195/1647-8630_23_9

Organização dos Estados Americanos. (1995, June). Convenção Interamericana para Prevenir, Punir e Erradicar a Violência Contra a Mulher "Convenção de Belém do Pará. Assembléia Geral Da Organização Dos Estados Americanos. Recuperado de http://www.direitoshumanos.usp.br/index.p hp/OEA-Organização-dos-EstadosAmericanos/convencao-interamericanapara-prevenir-punir-e-erradicar-a-violenciacontra-a-mulher-qconvencao-de-belem-doparaq-1994.html

Organização Pan-Americana da Saúde. (2015). Estratégias e plano de ação para o reforço do sistema de saúde para abordar a violência contra a mulher. Recuperado de https://iris.paho.org/bitstream/handle/10665 $.2 / 18386 /$ CD549Rev2_por.pdf?sequence $=9$ \&isAllowed $=\mathrm{y}$

Paim, K. (2016). A terapia do esquema para casais. In R. Wainer, K. Paim, R. Erdos, \& R. Andriola (Eds.), Terapia Cognitiva focada em Esquemas: integração em psicoterapia (s.p). Porto Alegre: Artmed.

Paim, K. (2019). A química esquemática e as escolhas amorosas. In K. Paim \& B. L. A. Cardoso (Eds.), Terapia do Esquema para Casais: Base Teórica e Intervenção (1st ed., Vol. 1, pp. 31-44). Porto Alegre: Artmed.

Paim, K., \& Cardoso, B. L. A. (2019). Terapia do Esquema para Casais (1st ed., Vol. 1). Porto Alegre: Artmed.

Paim, K., \& Falcke, D. (2016). Perfil discriminante de sujeitos com histórico de violência conjugal: O papel dos Esquemas Iniciais Desadaptativos. Revista Brasileira de Terapia Comportamental e Cognitiva, 18(2), 112-129. doi: 10.31505/rbtcc.v18i2.887

Paim, K., \& Falcke, D. (2018). The experiences in the family of origin and the early maladaptive schemas as predictors of marital violence in men and women. Analise Psicologica, 36(3), 279-293. doi: 10.14417/ap.1242

Paim, K., Madalena, M., \& Falcke, D. (2012). Esquemas iniciais desadaptativos na violência conjugal. Revista Brasileira de Terapias Cognitivas, 8(1), 31-39.

Recuperado de http://pepsic.bvsalud.org/scielo.php?script= $\underline{\text { sci_abstract\&pid }=\text { S1808- }}$ $56872012000100005 \& \ln \mathrm{g}=\mathrm{pt} \& \mathrm{nrm}=\mathrm{iso}$

Paim, K., \& Torquato, K. I. (2019). Estratégias e técnicas para mudança em terapia do esquema. In K. Paim \& B. L. A. Cardoso (Eds.), Terapia do Esquema para Casais: base teórica e intervenção (1st ed., Vol. 1, pp. 101-119). Porto Alegre:

Artmed.

Pesquisa DataSenado. (2017). Violência doméstica e familiar contra a mulher.Recuperado de https://www12.senado.leg.br/institucional/d atasenado/arquivos/aumenta-numero-de- 
mulheres-que-declaram-ter-sofridoviolencia

Rafaeli, E., Bernstein, D., \& Young, J. (2010). Schema Therapy: Distinctive Features (E. Rafaeli, D. Bernstein, \& J. Young (eds.); 1st ed.). Londres: Routledge.

Rother, E. T. (2007). Systematic literature review X narrative review. ACTA Paulista de Enfermagem, 20(2), pp. 5-6. doi: 10.1590/s0103-21002007000200001

Schraiber, L. B., Barros, C. R. dos S., \& de Castilho, E. A. (2010). Violência contra as mulheres por parceiros íntimos: Usos de serviços de saúde. Revista Brasileira de Epidemiologia, 13(2), 1-9. doi: 10.1590/s1415-790x2010000200006

Scott, J. (1995). Gênero: uma categoria útil de análise histórica. Educação e Realidade, 20(2), 71-99. Recuperado de https://seer.ufrgs.br/educacaoerealidade/arti cle/view/71721/40667

Scribel, M. do C., Sana, M. R., \& Benedetto, A. M. di. (2007). Schemas in the structure of conjugal blonds. Revista Brasileira de Terapias Cognitivas, 3(2), s.p. doi: 10.5935/1808-5687.20070012

Silva, M. A. R. B. da, \& Sanches, M. A. (2014). NÃO DESISTA DE SER FELIZ: um ensaio sobre a permanência de mulheres em relacionamentos com homens violentos. Caderno Teológico da PUCRP, 2(1), 113-134. Recuperado de https://docplayer.com.br/17257673-Naodesista-de-ser-feliz-um-ensaio-sobre-apermanencia-de-mulheres-emrelacionamentos-com-homensviolentos.html

Souza, P. A. de, \& Rosa, M. A. da. (2006). Os motivos que mantêm as mulheres vítimas de violência no relacionamento violento.
Revista de Ciências Humanas, 40, 509-527. doi: $10.5007 / \% 25 \mathrm{x}$

Van Vreeswijk, M., Broersen, J., \& Nadort, M. (2012). The Wiley-Blackwell Handbook of Schema Therapy: Theory, Research and Practice. New Jersey:Wiley-BlackWell.

Wainer, R. (2016). O desenvolvimento da personalidade e suas tarefas evolutivas. In R. Wainer, K. Paim, R. Erdos, \& R. Andriola (Eds.), Terapia Cognitiva Focada em Esquemas: integração em psicoterapia (1st ed., s.p.). Porto Alegre: Artmed.

Wainer, R., Paim, K., \& Erdos, R. (2016). Estratégias Terapêuticas: reparentalização limitada e confrontação empática. In R. Wainer, K. Paim, R. Erdos, \& R. Andriola (Eds.), Terapia Cognitiva Focada em Esquemas: integração em psicoterapia (1st ed., s.p.). Porto Alegre: Artmed.

Wainer, R., \& Rijo, D. (2016). O modelo teórico: esquemas iniciais desadaptativos, estilo de enfrentamento e modos esquemáticos. In R. Wainer, K. Paim, R. Erdos, \& R. Andriola (Eds.), Terapia Cognitiva Focada em Esquemas: integração em psicoterapia (1st ed., s.p.). Porto Alegre: Artmed.

World Health Organization. (2013). Global and regional estimates of violence against women. Recuperado de https://www.who.int/publications/i/item/97 $\underline{89241564625}$

Young, J. (2003). Terapia Cognitiva para Transtornos da Personalidade: uma abordagem focadano esquema (3rd ed.). Porto Alegre: Artmed.

Young, J. E., Klosko, J. S., \& Weishaar, M. E. (2008). Terapia do Esquema: Guia de Técnicas Cognitivo-Comportamentais Inovadoras (1st ed.). Porto Alegre: Artmed. 


\section{Dados sobre os autores:}

- Daniela Baldissera: Psicóloga Clínica, graduada pelo Centro Universitário Metodista - IPA.

- Kelly Paim: Psicóloga, especialista em Terapia Cognitivo-Comportamental e especialista em Psicoterapia de Casal e Família. Também é mestre em Psicologia Clínica. Possui formação em Terapia do Esquema pela Wainer Psicologia Cognitiva e NYC Institute for Schema Therapy. Faz parte do corpo clínico da Valência Psicologia, trabalhando com atendimento individual, de casais e familiar. É professora do Curso de Formação em Terapia do Esquema da Wainer Psicologia Cognitiva.

- Betina Munero Predebon: Psicóloga Clínica, graduada pela PUCRS, especialista em Terapia Cognitivo-Comportamental pela Wainer Psicologia.

- Leandro da Fonte Feix: Professor-orientador. Possui graduação em Psicologia e especialização em Psicologia Clínica com ênfase em Psicoterapia Cognitivo-Comportamental. É mestre em Psicologia. Atua como psicólogo na Clínica Sensum Psicologia e como docente do curso de Psicologia do Centro Universitário Metodista - IPA. direitos autorais para os artigos publicados são do autor, com direitos do periódico sobre a primeira publicação. Os autores somente poderão utilizar os mesmos resultados em outras publicações indicando claramente este periódico como o meio da publicação original. Em virtude de sermos um periódico de acesso aberto, permite-se o uso gratuito dos artigos em aplicações educacionais e científicas desde que citada a fonte conforme a licença CC-BY da Creative Commons. 